\title{
Facilitating Informed Decision Making: Determinants of University Students' COVID-19 Vaccine Uptake
}

Tugce Varol*a ${ }^{*}$ https://orcid.org/0000-0003-0737-9802

Francine Schneider ${ }^{\mathrm{b}}$, https://orcid.org/0000-0001-5901-6267

Ilse Mesters ${ }^{\mathrm{c}}$, https://orcid.org/0000-0003-0605-6286

Robert A.C. Ruiter ${ }^{\mathrm{a}}$, https://orcid.org/0000-0001-5017-3258

Gerjo Kok ${ }^{\mathrm{a}}$, https://orcid.org/0000-0002-3501-4096

Gill A. ten Hoor ${ }^{\mathrm{a}}$, http://orcid.org/0000-0001-5500-1893

a. Department of Work and Social Psychology, Maastricht University, the Netherlands

b. Department of Health Promotion, CAPHRI, Maastricht University, The Netherlands

c. Department of Epidemiology, CAPHRI, Maastricht University, The Netherlands

*Corresponding author: Tugce Varol, Dept. of Work \& Social Psychology, Maastricht

University, P.O. Box 616, 6200 MD Maastricht, The Netherlands

t.varol@maasrichtuniversity.nl 


\begin{abstract}
Objective: Although several COVID-19 vaccines are available, the current challenge is achieving high vaccine uptake. We aimed to explore university students' intention to get vaccinated and select the most relevant determinants/beliefs to facilitate informed decisionmaking around COVID-19 vaccine uptake.
\end{abstract}

Methods: A cross-sectional online survey with students $(N=434)$ from Maastricht University was conducted in March 2021. The most relevant determinants/beliefs of students' COVID-19 vaccine intention (i.e., determinants linked to vaccination intention, and with enough potential for change) were visualized using CIBER plots.

Results: Students' intention to get the COVID-19 vaccine is high (80\%). Concerns about safety and side effects of the vaccine and trust in government, quality control, and the pharmaceutical industry are identified as the most relevant determinants of vaccine intention. Other predictors are risk perception, attitude, perceived norm, and self-efficacy beliefs.

Conclusion: Our study identified several predictors of COVID-19 vaccine intention (e.g., safety, trust, risk perception, etc.) and helped to select the most relevant determinants/beliefs to target in an intervention to maximize the COVID-19 uptake. Where concerns and trust related to the COVID-19 vaccine are the most important target for future interventions, other determinants that were already positive (i.e., risk perception, attitudes, perceived norms, and self-efficacy) could be further confirmed.

Key words: Vaccine, COVID-19, intention, determinants, university students 


\section{Introduction}

The world has been trying to combat the COVID-19 pandemic since late December 2019 (Rothan and Byrareddy, 2020). Governments implemented public health measures that were deemed to be the only way to prevent the spread of SARS-COV-2 until the roll-out of the COVID-19 vaccines (Bedford et al., 2020; Kissler et al., 2020). However, new developments brought new challenges, such as COVID-19 vaccine hesitancy, defined by the WHO Strategic Advisory Group of Experts (SAGE) on Immunization as the delay in acceptance or refusal of vaccines despite availability of vaccine services (MacDonald, 2015; WHO, 2014).

Since several COVID-19 vaccines were developed or are currently under development, people's intention to get the COVID-19 vaccine as a vital step is the focus of health professionals and governments. High vaccine uptake is deemed important to control the spread of COVID-19 (Chevallier et al., 2021; DeRoo et al., 2020). Several studies demonstrated that people's intention to get vaccinated against COVID-19 is positive, yet not positive enough (Malik et al., 2020; Paul et al., 2021) and that there is room for improvement. To increase vaccine uptake, identifying the so-called determinants/beliefs behind people's intention to engage in health behavior, such as vaccination against COVID-19, is the key to develop successful evidence and-theory-based interventions (Kok, 2014; Peters, 2014). As behavior change methods do not directly operate on the behavior itself but on its determinants, intervention developers first need to map the determinants of behavior/intention and then select the most relevant ones for an intervention (Kok et al., 2016; Peters 2014). In this study, we systematically determined and selected the most relevant determinants/beliefs of COVID-19 vaccine intention of university students.

\section{Theories behind the study}

The Reasoned Action Approach (Fishbein and Ajzen, 2010; Theory of Planned Behavior, Ajzen, 2015) postulates that behavior is influenced by one's intention to engage in that behavior, and intention is influenced by three determinants with underlying beliefs: a) attitude, one's (positive/negative) evaluation of the consequences of engaging a behavior; $b$ ) perceived norm, one's perception that important others might (dis)approve of them for engaging in a behavior (injunctive norm) and one's perception that others like themselves do (or do not) engage in a behavior (descriptive norm); c) perceived behavioral control (or selfefficacy), one's perception about whether they are capable of, or have control over, executing a behavior. Protection Motivation Theory (Maddux and Rogers, 1983; Ruiter et al., 2014), on risk perception, declares that a) threat appraisal, people's perception of the severity of a threat (perceived severity) and people's perception of how susceptible they are to a threat (perceived susceptibility), and b) coping appraisal, people's expectation of whether engaging in a behavior will lead a change (response efficacy) and people's perception of whether they can perform a behavior successfully (self-efficacy), determine people's risk perception and how they will respond to a threat. In the case of vaccination intention, determinants related to automaticity and habit do not seem to be essential.

\section{Current study}

The aims of this study are to (1) examine university students' intention to get the COVID-19 vaccine and (2) select the most relevant (i.e., correlated to one's intention, and showing room 
for improvement) determinants/beliefs of students' intention to get vaccinated to target in intervention. By COVID-19 vaccine, we refer to vaccines that are approved for use in the EU at the time that this study was executed.

\section{Methods}

\section{Participants and recruitment}

Maastricht University students were recruited (March 8th until March 29th, 2021) through a student panel operated by Flycatcher (2021) (an online survey platform https://www.flycatcher.eu/en/Home/OverOns). The student panel is refreshed at the beginning of each academic year by including new students and is representative of all the study years. All panel members of the student panel were invited to the survey. Three reminders were sent to the students (on March 15, 22, and 25). Students who completed the survey received a small incentive for their participation. This study was approved by the Ethics Review Committee Psychology \& Neuroscience, Maastricht University (reference number 188_10_02_2018_S59).

\section{Design and procedure}

The cross-sectional online survey could be accessed upon clicking the hyperlink sent with an e-mail invitation. After informed consent, students received questions on the topics of (1) their views on the risk of contracting COVID-19 and its severity (risk perception); (2) concerns and trust around the COVID-19 vaccine (concerns and trust); (3) their opinions about getting the COVID-19 vaccine (attitude); (4) what they think about what other people will do or want them to do regarding getting the COVID-19 vaccine (perceived norm); (5) potentially difficult situations regarding getting the COVID-19 vaccine (self-efficacy); and (6) their intentions to get the COVID-19 vaccination (intention). Students were also asked about their demographic information. All questions were in English to reach all the students (both Dutch and international) within the university (note that all students have a good command of English).

\section{Measurements}

The questionnaire was developed based on the available literature on COVID-19-vaccine hesitancy and vaccine hesitancy in general (Daly and Robinson, 2021; Dror et al., 2020; Neumann-Böhme et al., 2020; Quinn et al., 2019; Taylor et al., 2020) and revised based on the pretest with students. The underlying theories behind the questionnaire were the Reasoned Action Approach (RAA) and the Protection Motivation Theory (PMT). Questions can be found in Table 2 and Supplementary Materials File 1.

Intention was assessed with the item "I intend to get the COVID-19 vaccination when invited to do so", which was answered on a 7-point Likert scale (fully disagree [1] - fully agree [7]). Another two intention questions were asked based on two different scenarios regarding waiting to get the COVID-19 vaccine: (1) "When it is my turn, I think I will wait to see if others experience any negative side effects due to getting the COVID-19 vaccination" and (2) "When it is my turn, I think I want to wait until next year before I make a decision about getting the COVID-19 vaccination" with a 7-point Likert answer option and in case, they are not willing to get the COVID-19 vaccine, "I don't intend to take the vaccination" 
response option was included.

Risk perception was assessed with five items such as "I think that without vaccination, I might be at risk of contracting COVID-19"; "I think that if I contract COVID-19, the physical consequences for me would be severe"; and "I know people who have severe health problems due to COVID-19". All items were answered on a 7-point Likert scale; fully disagree (1) - fully agree (7).

Concerns and trust is partly underlying attitude and risk perception, and focused on students' evaluations about the development, safety, possible short- and/or long-term side effects of the COVID-19 vaccine as well as students' trust in government, pharmaceutical industry, and quality control with regard to the COVID-19 vaccine. It includes 14 items; example items are "I am worried about the speed of the development of the vaccine"; "I am worried about the safety of the COVID-19 vaccine"; "I am worried about possible long-term (more than a week) negative side effects of the COVID-19 vaccine"; "I trust the government about ensuring the safety of the COVID-19 vaccine". Except for "How many people do you know who already received the COVID-19 vaccine and had no serious complaints afterwards?" item (answer option: none [1] - many [7] and I do not know people who already received the COVID-19 vaccine), all items were responded on a 7-point Likert scale (fully disagree [1] - fully agree [7]).

Attitude consisted of seven items, for instance, "I think that by getting the COVID-19 vaccine, I protect myself against contracting COVID-19"; "I think that getting the COVID-19 vaccine is a way out of this pandemic"; and "I think that getting the COVID-19 vaccine is my moral duty". All attitude items were answered on a 7-point Likert scale (fully disagree [1] fully agree [7]).

Perceived norm included three items with the answer options (fully disagree [1] fully agree [7]): "I think that most people like me will get the COVID-19 vaccination"; "I think that my doctor/health care provider wants me to get the COVID-19 vaccination"; and "I think that most people who are important to me want me to get the COVID-19 vaccination".

Self-efficacy was measured with six items, e.g., "If I would decide to get the COVID19 vaccination, I am confident that I could get it when it is my turn"; "I feel comfortable talking to my family and/or friends about whether or not to get the COVID-19 vaccination"; and "I am confident that before I decide to get the COVID-19 vaccine, I will have sufficient information about the COVID-19 vaccine". A 7-point Likert scale was used for the answer options (fully disagree [1] - fully agree [7]).

Demographics were measured by asking age, gender, study year, faculty, living condition and nationality (Dutch or international).

\section{Data analysis}

Descriptive statistics were analyzed by using IBM SPSS Statistics 26, and the associations between intention and all determinants/beliefs were calculated and reported. The Confidence Interval-Based Estimation of Relevance (CIBER, [Peters and Crutzen, 2018]) approach was used to establish the determinant/belief relevance depending on 1) the association between the 
intention to get the COVID-19 vaccine and determinants (e.g., risk perception) and 2) the room for improvement based on the univariate distribution of each determinant/belief. For instance, if a determinant/belief has no correlation with intention but has room for improvement, this determinant/belief would unlikely be a determinant to intervene on, whereas a determinant/belief correlated with intention and has a mean score on the middle of the scale or on the undesirable direction would be a relevant target. Therefore, combining these two types of information is necessary for establishing the determinant/belief relevance (Crutzen et al., 2017). While determining the relevance of a determinant/belief, it is important to check all the available information (and context) simultaneously, where CIBER plots help inspect the information by visualizing the univariate distribution of each determinant/belief; the correlation between behavior/determinant and determinants; confidence intervals for the mean; and confidence intervals for bivariate correlations (Peters and Crutzen, 2018). The CIBER approach also allows intervention developers to study the determinants at a high level of specificity, i.e., sub-determinants or beliefs, that can be used in the intervention messages (Crutzen et al., 2017), as we did in our study (see Table 3). Contrary to commonly used multiple regression analysis in determinant studies which assesses the total explained variance in the dependent variable based on the predictors in the model, the CIBER approach assesses the determinant/belief relevance on the individual predictor level and postulates that the multiple regression analysis can be problematic to establish the determinant/belief relevance due to the overlap between the predictors (for details see; Peters and Crutzen, 2018). To create the CIBER plots, the 'behaviorchange' R package (Peters, 2021) was used.

\section{Results}

\section{Background characteristics of the sample}

A total of 908 students were invited to the survey and 483 responded (53.2\% response rate). From those, 43 incomplete responses and 2 responses with poor response quality (i.e., straight lining/patterns) were removed. Another 4 did not consent to participate leading to a final sample of 434 students $(47.8 \%$ ). The mean age of eligible students was 22 (range: 18-42 years) (panel [based on data of UM Flycatcher student panel members] = 22; range 18-43 years). A total of $75.3 \%$ of students were female (panel $=73.3 \%)$. Dutch $(51.8 \%)$ and international students were equally represented. Detailed background information about the sample is provided in Table 1.

Table 1. Background characteristics of the sample $(N=434)$

\begin{tabular}{ll}
\hline Students & N (\%) \\
\hline Gender $($ female $)$ & $327(75.3 \%)$ \\
\hline Age in years $(\boldsymbol{M}+\boldsymbol{S D})$ & $22.1(3.5)$ \\
\hline Study year & \\
\hline Bachelor year 1 & $96(22.1 \%)$ \\
Bachelor year 2 & $84(19.4 \%)$ \\
Bachelor year 3 & $99(22.8 \%)$ \\
Pre-master & $1(0.2 \%)$ \\
Master year 1 & $72(16.6 \%)$
\end{tabular}




\begin{tabular}{ll} 
Master year 2 & $51(11.8 \%)$ \\
Master year 3 & $24(5.5 \%)$ \\
Master year 4 & $7(1.6 \%)$ \\
\hline Living situation & $88(20.3 \%)$ \\
\hline I live alone & $102(23.5 \%)$ \\
I live with my parent(s)/caretaker(s) & $54(12.4 \%)$ \\
I live with my partner & $4(0.9 \%)$ \\
I live with my partner and kid(s) & $1(0.2 \%)$ \\
I live with my kid(s) & $185(42.6 \%)$ \\
I live with people other than the abovementioned & $178(41 \%)$ \\
\hline Faculty & $41(9.4 \%)$ \\
\hline Faculty of Health, Medicine and Life Sciences (FHML) & $50(11.5 \%)$ \\
Faculty of Arts and Social Sciences (FASoS) & $60(13.8 \%)$ \\
Faculty of Psychology and Neuroscience (FPN) & $49(11.3 \%)$ \\
School of Business and Economics (SBE) & $56(12.9 \%)$ \\
Faculty of Law (FdR) & \\
Faculty of Science and Engineering (FSE) & $225(51.8 \%)$ \\
\hline Nationality & $209(48.2 \%)$ \\
\hline Dutch student & \\
International student & \\
\hline
\end{tabular}

\section{Intention to get the COVID-19 vaccine}

Of the 434 students, 348 (80.1\%; score 6 - 7 [fully agree]) intended to get the COVID-19 vaccination when invited to do so. The mean and median scores of students' intention were $M$ $=6.20(1-7) ; S D=1.44 ; M d n(I Q R)=7.00(6-7) ; 11 \%$ of students agreed (6-7) with the item "When it is my turn, I think I will wait to see if others experience any negative side effects due to getting the COVID-19 vaccination"; 3.9\% agreed (6-7) with "When it is my turn, I think I want to wait until next year before I make a decision about getting the COVID-19 vaccination".

\section{Selecting the most relevant determinants/beliefs}

Almost all determinants that were selected for this study (based on theory and earlier research [Daly and Robinson, 2021; Dror et al., 2020; Neumann-Böhme et al., 2020; Quinn et al., 2019; Taylor et al., 2020]) 1) were correlated with the intention to get vaccinated, 2) were relatively positive with regards to vaccination intention, and 3) had potential room for improvement. With that, all items that are correlated with intention and have room for improvement, are potentially relevant as potential targets for future interventions. All mean, median, SD, IQR and $r$ are shown in Table 2 and CIBER plots for all the determinants can be found in the Supplementary Materials.

\section{Concern and trust}

Although most belief items were significantly correlated with vaccination intention, often the correlation coefficient was relatively low, or the mean score was relatively high (see Table 2). The determinant with high correlations and most room for improvement was "concern and trust" (except for one item where $12.4 \%$ indicated to not know anyone who already received 
the COVID-19 vaccine, mean scores were between 2.86 and 5.53, $r$ 's ranged from -.27 to $.67)$, and therefore an important intervention target. Items included 1) the safety and effectiveness of the vaccine, 2) possible side effects, and 3) trust in the government, the quality control and the pharmaceutical industry. Regarding three additional items comparing current vaccines in the National Immunization Program against diseases (such as measles, pertussis, diphtheria and other diseases) with the COVID-19 vaccine showed that participants were neutral in terms of whether the COVID-19 vaccines are equally safe; effective and trusted (i.e., mean scores close the middle of the scale, showing that there is room for improvement; see Figure 1).

\section{Other items that should be considered as target for future intervention}

All risk perception items, except "I had people in my social environment who had serious negative experiences related to COVID-19" were significantly correlated with vaccination intention ( $r$ ranges from .15 - .43). Additionally, all items scored neutral or positive and had room for improvement, making them important targets for future interventions. Attitude, perceived norm, and self-efficacy items all had high correlations ( $r$ 's ranging from .27 to .72), but also had high mean scores ( $M$ 's ranging from $5.13-6.08$ ), making those determinants important targets for confirmation in interventions, but not for improvement per se.

Table 2. Mean, standard deviation, interquartile range, median values of determinants and their associations with intention

\begin{tabular}{|c|c|c|c|c|c|c|}
\hline & $\mathrm{M}$ & SD & IQ1 & Mdn & IQ3 & $\mathrm{r}$ \\
\hline \multicolumn{7}{|l|}{ Risk perception } \\
\hline $\begin{array}{l}\text { I think that without vaccination, I might be at risk of } \\
\text { contracting COVID- } 19 \text {. }\end{array}$ & 5.66 & 1.50 & 5.00 & 6.00 & 7.00 & $.43 * *$ \\
\hline $\begin{array}{l}\text { I think that if I contract COVID-19, the physical } \\
\text { consequences for me would be severe. }\end{array}$ & 3.34 & 1.56 & 2.00 & 3.00 & 4.00 & $.15^{*}$ \\
\hline $\begin{array}{l}\text { I think that if I contract COVID-19, the social } \\
\text { consequences for me would be severe. }\end{array}$ & 4.37 & 1.67 & 3.00 & 4.50 & 6.00 & $.18^{* *}$ \\
\hline $\begin{array}{l}\text { I know people who have severe health problems due } \\
\text { to COVID-19. }\end{array}$ & 4.04 & 2.18 & 2.00 & 4.00 & 6.00 & $.18 * *$ \\
\hline $\begin{array}{l}\text { I had people in my social environment (family, } \\
\text { friends) who had serious negative experiences related } \\
\text { to COVID-19. }\end{array}$ & 4.12 & 2.09 & 2.00 & 4.00 & 6.00 & .10 \\
\hline \multicolumn{7}{|l|}{ Attitude } \\
\hline $\begin{array}{l}\text { I think that by getting the COVID-19 vaccine, I } \\
\text { protect myself against contracting COVID- } 19 .\end{array}$ & 5.88 & 1.40 & 5.00 & 6.00 & 7.00 & $.55^{* *}$ \\
\hline $\begin{array}{l}\text { I think that by getting the COVID-19 vaccine, I } \\
\text { protect the people around me from contracting } \\
\text { COVID- } 19 \text {. }\end{array}$ & 5.81 & 1.51 & 5.00 & 6.00 & 7.00 & $.50 * *$ \\
\hline $\begin{array}{l}\text { I think that getting the COVID-19 vaccine is a way } \\
\text { out of this pandemic. }\end{array}$ & 5.98 & 1.43 & 5.00 & 7.00 & 7.00 & $.61 * *$ \\
\hline $\begin{array}{l}\text { I think that by getting the COVID- } 19 \text { vaccine, there } \\
\text { will be fewer restrictions for me. }\end{array}$ & 5.13 & 1.67 & 4.00 & 5.00 & 7.00 & $.27 * *$ \\
\hline $\begin{array}{l}\text { I think that by getting the COVID- } 19 \text { vaccine, I can } \\
\text { safely have more social contacts. }\end{array}$ & 5.33 & 1.58 & 4.00 & 6.00 & 7.00 & $.43 * *$ \\
\hline
\end{tabular}




\begin{tabular}{|c|c|c|c|c|c|c|}
\hline $\begin{array}{l}\text { I think that getting the COVID-19 vaccine is my } \\
\text { moral duty. }\end{array}$ & 5.41 & 1.90 & 4.00 & 6.00 & 7.00 & $.72^{* *}$ \\
\hline $\begin{array}{l}\text { I would feel guilty if I transmitted the virus to others } \\
\text { if I decided not to get the COVID-19 vaccine. }\end{array}$ & 5.88 & 1.66 & 5.00 & 7.00 & 7.00 & $.72 * *$ \\
\hline \multicolumn{7}{|l|}{ Concerns and trust } \\
\hline $\begin{array}{l}\text { I am worried about the speed of the development of } \\
\text { the vaccine. }\end{array}$ & 3.65 & 1.96 & 2.00 & 3.00 & 5.00 & $-.27 * *$ \\
\hline $\begin{array}{l}\text { I am worried about the safety of the COVID-19 } \\
\text { vaccine. }\end{array}$ & 3.31 & 1.89 & 2.00 & 3.00 & 5.00 & $-.58 * *$ \\
\hline $\begin{array}{l}\text { I am worried about possible short-term (within a } \\
\text { week) negative side effects of the COVID-19 vaccine. }\end{array}$ & 2.86 & 1.71 & 2.00 & 2.00 & 4.00 & $-.28 * *$ \\
\hline $\begin{array}{l}\text { I am worried about possible long-term (more than a } \\
\text { week) negative side effects of the COVID-19 vaccine. }\end{array}$ & 3.87 & 1.98 & 2.00 & 4.00 & 5.00 & $-.55^{* *}$ \\
\hline $\begin{array}{l}\text { I think that fever and muscle pain after vaccination } \\
\text { actually show that the vaccine is working. }\end{array}$ & 4.33 & 1.70 & 3.00 & 4.00 & 6.00 & $.28^{* *}$ \\
\hline $\begin{array}{l}\text { I think that the COVID- } 19 \text { vaccine will be effective } \\
\text { against new mutations of the virus. }\end{array}$ & 3.87 & 1.32 & 3.00 & 4.00 & 5.00 & $.40 * *$ \\
\hline $\begin{array}{l}\text { I think that if people already have other serious health } \\
\text { issues, they should be hesitant about getting the } \\
\text { COVID-19 vaccine. }\end{array}$ & 3.24 & 1.56 & 2.00 & 3.00 & 4.00 & $-.29 * *$ \\
\hline $\begin{array}{l}\text { How many people do you know who already received } \\
\text { the COVID-19 vaccine and had no serious complaints } \\
\text { afterwards? }{ }^{\dagger} \text { (none: } 1 \text { - many: } 7 \text { ) }\end{array}$ & 3.88 & 1.97 & 2.00 & 4.00 & 5.00 & $.16^{*}$ \\
\hline $\begin{array}{l}\text { I trust the government about ensuring the safety of the } \\
\text { COVID-19 vaccine. }\end{array}$ & 5.03 & 1.62 & 4.00 & 5.00 & 6.00 & $.62^{* *}$ \\
\hline $\begin{array}{l}\text { I trust the quality control around the COVID-19 } \\
\text { vaccine. (EMA and the NCAs.) }\end{array}$ & 5.53 & 1.46 & 5.00 & 6.00 & 7.00 & $.67 * *$ \\
\hline $\begin{array}{l}\text { I trust the pharmaceutical industry about the safety of } \\
\text { the COVID-19 vaccine. }\end{array}$ & 4.67 & 1.59 & 4.00 & 5.00 & 6.00 & $.53 * *$ \\
\hline $\begin{array}{l}\text { Compared to current vaccines in the National } \\
\text { Immunization Program against diseases such as } \\
\text { measles, pertussis, diphtheria and other diseases, I } \\
\text { consider the COVID-19 vaccine equally safe. }\end{array}$ & 4.96 & 1.61 & 4.00 & 5.00 & 6.00 & $.63^{* *}$ \\
\hline $\begin{array}{l}\text { Compared to current vaccines in the National } \\
\text { Immunization Program against diseases such as } \\
\text { measles, pertussis, diphtheria and other diseases, I } \\
\text { consider the COVID-19 vaccine equally effective. }\end{array}$ & 4.91 & 1.44 & 4.00 & 5.00 & 6.00 & $.52 * *$ \\
\hline $\begin{array}{l}\text { Compared to current vaccines in the National } \\
\text { Immunization Program against diseases such as } \\
\text { measles, pertussis, diphtheria and other diseases, I } \\
\text { consider the COVID-19 vaccine equally trusted. }\end{array}$ & 4.54 & 1.63 & 3.00 & 5.00 & 6.00 & $.54 * *$ \\
\hline \multicolumn{7}{|l|}{ Perceived norm } \\
\hline $\begin{array}{l}\text { I think that most people like me will get the COVID- } \\
19 \text { vaccination. }\end{array}$ & 5.53 & 1.39 & 5.00 & 6.00 & 7.00 & $.54 * *$ \\
\hline $\begin{array}{l}\text { I think that my doctor/health care provider wants me } \\
\text { to get the COVID-19 vaccination. }\end{array}$ & 5.38 & 1.62 & 4.00 & 6.00 & 7.00 & $.46^{* *}$ \\
\hline $\begin{array}{l}\text { I think that most people who are important to me want } \\
\text { me to get the COVID-19 vaccination. }\end{array}$ & 5.56 & 1.61 & 5.00 & 6.00 & 7.00 & $.65^{* *}$ \\
\hline \multicolumn{7}{|l|}{ Self-efficacy } \\
\hline $\begin{array}{l}\text { If I would decide to get the COVID-19 vaccination, I } \\
\text { am confident that I could get it when it is my turn. }\end{array}$ & 5.69 & 1.41 & 5.00 & 6.00 & 7.00 & $.39 * *$ \\
\hline
\end{tabular}




\begin{tabular}{|c|c|c|c|c|c|c|}
\hline $\begin{array}{l}\text { If I would decide to get the COVID-19 vaccination, it } \\
\text { is easy for me to get the COVID-19 vaccine when it is } \\
\text { my turn. }\end{array}$ & 5.54 & 1.46 & 5.00 & 6.00 & 7.00 & $.28^{* *}$ \\
\hline $\begin{array}{l}\text { I am confident that before I decide to get the COVID- } \\
19 \text { vaccine, I will have sufficient information about } \\
\text { the COVID-19 vaccine. }\end{array}$ & 5.40 & 1.55 & 5.00 & 6.00 & 7.00 & $.50^{* *}$ \\
\hline $\begin{array}{l}\text { I am confident that before I decide to get the COVID- } \\
19 \text { vaccine, I can always ask for more information } \\
\text { from my general practitioner or the Public Health } \\
\text { Service. }\end{array}$ & 5.58 & 1.45 & 5.00 & 6.00 & 7.00 & $.41^{* *}$ \\
\hline $\begin{array}{l}\text { I feel comfortable talking to my family and/or friends } \\
\text { about whether or not to get the COVID-19- } \\
\text { vaccination. }\end{array}$ & 6.08 & 1.29 & 6.00 & 7.00 & 7.00 & $.31 * *$ \\
\hline $\begin{array}{l}\text { I am not concerned about possible local pain that } \\
\text { could occur at the time I get the COVID-19- } \\
\text { vaccination if I decide to do so. }\end{array}$ & 5.44 & 1.78 & 5.00 & 6.00 & 7.00 & $.35^{* *}$ \\
\hline
\end{tabular}

${ }^{\top 54}(12.4 \%)$ students indicated that they do not know people who already received the COVID-19 vaccine. ${ }^{*} p<$ $.01 ; * p<.001$

Figure 1. CIBER plot of concerns and trust visualizing means and association with intention to get the COVID-19 vaccine

Means and associations $(r)$ with intention to get COVID-19 vaccine $\left(R^{2}=[.46 ; .6]\right)$

I am worried about the speed of the development of the vaccine.

I am worried about the safety of the COVID-19 vaccine.

I am worried about possible short-term (within a week) negative side effects of the COVID-19 vaccine.

I am worried about possible long-term (more than a week) negative side effects of the COVID-19 vaccine.

I think that fever and muscle pain after vaccination actually show that the vaccine is working

I think that the COVID-19 vaccine will be effective against new mutations of the virus.

I think that if people already have other serious health issues, they should be hesitant about getting the COVID-19 vaccine.

I trust the government about ensuring the safety of the COVID-19 vaccine.

I trust the quality control around the COVID-19 vaccine. (EMA and the NCAs.)

I trust the pharmaceutical industry about the safety of the COVID-19 vaccine.

Compared to current vaccines in the National Immunization Programme, I consider the COVID-19 vaccine equally safe.

Compared to current vaccines in the National Immunization Programme, I consider the COVID-19 vaccine equally effective.

Compared to current vaccines in the National Immunization Programme, I consider the COVID-19 vaccine equally trusted.

How many people do you know who already received the COVID-19 vaccine and had no serious complaints afterwards?

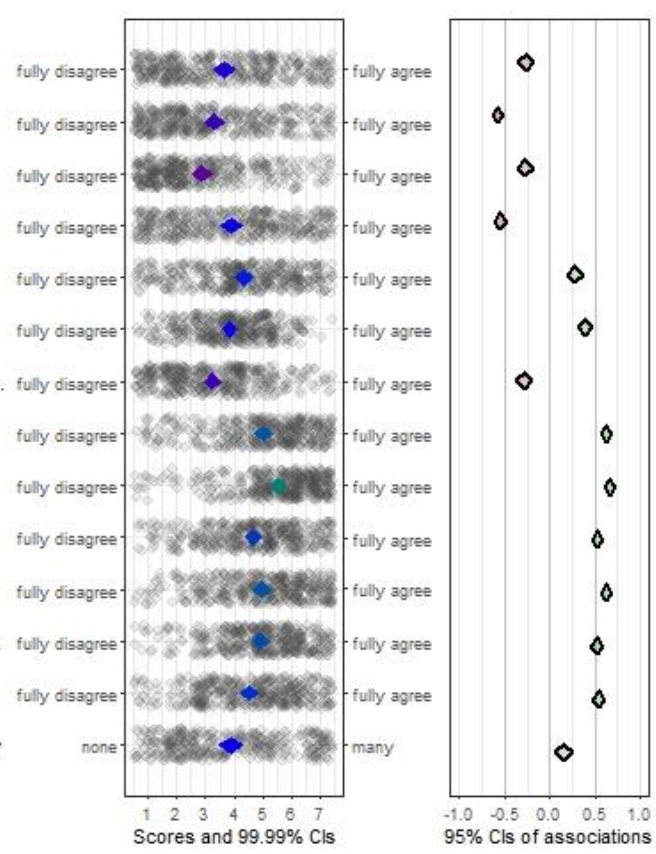

\section{Discussion}

As universities will reopen in the near future, it is vital to prepare a safe educational environment for students and staff. This includes helping students to make informed decisions about the COVID-19 vaccination. In this study, we identified the reasons (determinants/beliefs) behind students' possible hesitancy for the COVID-19 vaccine and selected the most relevant determinants/beliefs to further improve the uptake.

Based on the findings of this study, most students (80\%) intend to get the COVID-19 vaccine when it is their turn. Previous studies among university students also found relatively 
high willingness to be vaccinated against COVID-19 (Graupensperger et al., 2021; Barello et al., 2021; Pastorino et al., 2021). Nevertheless, people's intention to get the COVID-19 vaccine can be further enhanced by targeting its predictors.

Earlier studies on vaccine hesitancy illustrated attitude, perceived norm, self-efficacy as determinants of people's vaccination intention (Larson et al., 2014; Xiao and Wong, 2020). What is shown in our study in the context of COVID-19 is that students have positive attitudes, perceived norms and self-efficacy in relation to the COVID-19 vaccines. This is in line with what other studies found (see e.g., Guidry et al., 2021; Mo et al., 2021).

Additionally, risk perception was found to be a predictor of people's vaccine uptake, which was in line with findings of previous studies (Caserotti et al., 2021; Dubé et al., 2013; Reiter et al., 2020; Soares et al., 2021; Wang et al., 2020). Therefore, those determinants should be further confirmed in future interventions.

Our study demonstrated that the concerns about the safety and side effects of the COVID-19 vaccine on the one hand, and trust in the government about the safety of the vaccine, the quality control, and the pharmaceutical industry, are the most important intervention targets to improve students' intention to be vaccinated against COVID-19. Specifically, the possible long-term side effects and safety of the COVID-19 vaccines were the main concerns among students. This is in line with the findings from other studies in which the safety and trust were found as the most important predictors of intention to get the COVID-19 vaccine as well (Karlsson et al., 2021; Paul et al., 2021; Taylor et al., 2020). However, when students were asked whether the COVID-19 vaccines are equally safe, effective, and/or trusted compared to the current vaccines in the National Immunization Program, students mostly scored neutral, which might, or might not, be indicative of a general hesitancy about vaccines' safety, effectiveness, and trustiness worldwide (Dubé et al., 2013).

\section{An intervention to promote informed decision making}

Based on the findings of this study, the most relevant determinants/beliefs behind students' intention to get the COVID-19 vaccine are listed in Table 3. For each belief, a theoretical change method is selected that fits with the general determinant (Kok et al., 2016), for example "If I contract COVID-19, the physical consequences for me would be severe" had a mean that was relatively low, in combination with a relatively low correlation. Both should be higher. One method for increasing risk perception is "consciousness raising". All methods for change have so-called parameters for effectiveness that need to be fulfilled (Kok et al., 2016), for example consciousness raising should always be combined with (an improvement in) selfefficacy. In a qualitative part of this project (reported elsewhere) we asked which aspects students wanted to get information about, and by whom. Students indicated that they preferred science-based information from content experts, supported by high-level scientific publications. The actual intervention existed of a series of videos on a special website of the university on COVID-19 directed at students. The actual form was an interview by one student with, each time, an expert. The first part was about risk perception and worries and trust, with two experts in clinical microbiology, the second part on attitudes and perceived norms with two experts in health promotion/health psychology, and the third part was about perceived control was covered with clear online instructions how, where and when to get the vaccine, especially focused on international students.

\section{Limitations}


The limitations of this study include: first, rapid changes happen in terms of vaccine availability (e.g., the developments with AstraZeneca vaccine) as well as the COVID-19 regulations (e.g., relaxations in the measures) and depending on these developments and the related media coverage, the intention of students to get vaccinated against COVID-19 might also change over time. Therefore, follow-up studies in different time points might be needed to have a better view of students' intention level and its determinants. Second, we could only assess a limited number of determinants/beliefs since longer surveys might lead to a decline in the response rate. Therefore, there might be other important determinants/beliefs that might (positively or negatively) contribute to students' vaccine intention.

Table 3. An example of pairing the relevant determinants with behavior change principles to target in intervention 


\begin{tabular}{|c|c|c|c|}
\hline Determinant/item & Change & Method & Parameters \\
\hline \multicolumn{4}{|l|}{ Risk perception: } \\
\hline Without vaccination, I might be at risk of contracting COVID-19 & $5.7 \uparrow$ & [Belief selection/done] & \\
\hline If I contract COVID-19, the physical consequences for me would be severe & $3.3 \uparrow$ & Consciousness raising & -self-efficacy improvement \\
\hline & & Self-affirmation & -tailored to the individual \\
\hline \multicolumn{4}{|l|}{ Worries \& trust: } \\
\hline About the safety of the COVID-19 vaccine & $3.3 \downarrow$ & Scenario-based risk info & -plausible cause-effect \\
\hline About possible long-term negative side effects of the COVID-19 vaccine & $2.7 \downarrow$ & Persuasive communication & -relevant, not-discrepant, arguments \\
\hline The COVID-19 vaccine will be effective against new mutations of the virus & $3.9 \uparrow$ & \multirow[t]{2}{*}{ Tailoring } & -interactive (if possible?) \\
\hline I trust the government about ensuring the safety of the COVID-19 vaccine & $5.0 \uparrow$ & & \\
\hline I trust the quality control around the COVID-19 vaccine & $5.5 \uparrow$ & & \\
\hline I trust the pharmaceutical industry about the safety of the COVID-19 vaccine & $4.7 \uparrow$ & & \\
\hline \multicolumn{4}{|l|}{ [Compared to current vaccines in the National Immunization Program:] } \\
\hline I consider the COVID-19 vaccine equally safe & $5.0 \uparrow$ & & \\
\hline I consider the COVID-19 vaccine equally effective & $4.9 \uparrow$ & & \\
\hline I consider the COVID-19 vaccine equally trusted & $4.5 \uparrow$ & & \\
\hline \multicolumn{4}{|l|}{ Attitude/Outcome expectations: } \\
\hline I think that getting the COVID-19 vaccine is my moral duty & $5.4 \uparrow$ & -Self-reevaluation & -self-image/high self-efficacy \\
\hline I would feel guilty if I transmitted the virus if I decided not to get the vaccine & $5.9 \uparrow$ & -Anticipated regret & -imagery/positive about avoiding negative consequences \\
\hline \multicolumn{4}{|l|}{ Perceived norm/Social influence: } \\
\hline People like me will get the COVID-19 vaccination & $5.5 \uparrow$ & Info about others' approval & -are present \\
\hline My doctor/health care provider wants me to get the COVID-19 vaccination & $5.4 \uparrow$ & Resistance to social pressure & -commitment/values \\
\hline \multirow[t]{2}{*}{ People who are important to me want me to get the COVID-19 vaccination } & $5.6 \uparrow$ & Mobilizing social support & -available; trust \\
\hline & & Modeling & -reinforcement, identification, self-efficacy, coping \\
\hline \multicolumn{4}{|l|}{ Self-efficacy/Perceived control: } \\
\hline I am confident that I could get it when it is my turn & $6.0 \uparrow$ & Modeling & -reinforcement, identification, self-efficacy, coping \\
\hline It is easy for me to get the COVID-19 vaccine when it is my turn & $5.5 \uparrow$ & Guided practice & -demonstration, instruction, enactment \\
\hline I will have sufficient information about the COVID-19 vaccine & $5.4 \uparrow$ & Planning coping responses & -identification \& practice \\
\hline I can always ask for more information from my general practitioner/PHS & $5.6 \uparrow$ & \multirow[t]{2}{*}{ Goal setting } & -commitment to the goal \\
\hline I am not concerned about possible local pain that could occur & $5.4 \uparrow$ & & \\
\hline \multirow[t]{3}{*}{ From the university: } & \multicolumn{2}{|c|}{ Advocacy/active support } & style, consciousness raising/persuasion /approval \\
\hline & \multicolumn{2}{|c|}{ Technical assistance } & and resources \\
\hline & \multicolumn{2}{|c|}{ Mass-media role modeling } & e models being reinforced \\
\hline
\end{tabular}




\section{Conclusion}

In conclusion, the majority of Maastricht University students intend to get the COVID-19 vaccination. However, there is still some hesitation in relation to the safety and side effects of the COVID-19 vaccine as well as the trust in the government, quality control, and pharmaceutical industry, which can be addressed with scientific information from trusted sources that will assist in informed-decision making. All relevant determinants/beliefs can be targeted in interventions to facilitate the COVID-19 vaccine uptake.

\section{Ethics}

This study was approved by the Ethics Review Committee Psychology \& Neuroscience, Maastricht University, ref. 188_10_02_2018_S59.

\section{Acknowledgement}

The authors thank Rik Crutzen for his feedback on the formulation of the questionnaire and providing his support at different stages of the study. 


\section{References}

Ajzen, I. (2015). The theory of planned behaviour is alive and well, and not ready to retire: a commentary on Sniehotta, Presseau, and Araújo-Soares. Health psychology review, 9(2), 131-137. https://doi.org/10.1080/17437199.2014.883474

Barello, S., Nania, T., Dellafiore, F., Graffigna, G., \& Caruso, R. (2020). 'Vaccine hesitancy' among university students in Italy during the COVID-19 pandemic. European journal of epidemiology, 35(8), 781-783. https://doi.org/10.1007/s10654-020-00670-z

Bedford, J., Enria, D., Giesecke, J., Heymann, D. L., Ihekweazu, C., Kobinger, G. et al. (2020). COVID-19: towards controlling of a pandemic. The lancet, 395(10229), 10151018. https://doi.org/10.1016/S0140-6736(20)30673-5

Caserotti, M., Girardi, P., Rubaltelli, E., Tasso, A., Lotto, L., \& Gavaruzzi, T. (2021). Associations of COVID-19 risk perception with vaccine hesitancy over time for Italian residents. Social Science \& Medicine, 113688.

Chevallier, C., Hacquin, A. S., \& Mercier, H. (2021). COVID-19 vaccine hesitancy: Shortening the last mile. Trends in cognitive sciences. https://doi.org/10.1016/j.tics.2021.02.002

Crutzen, R., Peters, G. J. Y., \& Noijen, J. (2017). Using confidence interval-based estimation of relevance to select social-cognitive determinants for behavior change interventions. Frontiers in public health, 5, 165. https://doi.org/10.3389/fpubh.2017.00165

Daly, M., \& Robinson, E. (2021). Willingness to Vaccinate Against COVID-19 in the US: Representative Longitudinal Evidence From April to October 2020. American journal of preventive medicine. https://doi.org/10.1016/j.amepre.2021.01.008

DeRoo, S. S., Pudalov, N. J., \& Fu, L. Y. (2020). Planning for a COVID-19 vaccination program. Jama, 323(24), 2458-2459. https://doi.org/10.1001/jama.2020.8711

Dror, A. A., Eisenbach, N., Taiber, S., Morozov, N. G., Mizrachi, M., Zigron, A. et al. (2020). Vaccine hesitancy: the next challenge in the fight against COVID19. European journal of epidemiology, 35(8), 775-779. https://doi.org/10.1007/s10654-020-00671-y

Dubé, E., Laberge, C., Guay, M., Bramadat, P., Roy, R., \& Bettinger, J. A. (2013). Vaccine hesitancy: an overview. Human vaccines \& immunotherapeutics, 9(8), 1763-1773. https://doi.org/10.4161/hv.24657

Fishbein, M., \& Ajzen, I. (2010). Predicting and changing behavior: The reasoned action approach. New York: Taylor \& Francis Group.

Graupensperger, S., Abdallah, D. A., \& Lee, C. M. (2021). Social norms and vaccine uptake: College students' COVID vaccination intentions, attitudes, and estimated peer norms 
and comparisons with influenza vaccine. Vaccine, 39(15), 2060-2067. https://doi.org/10.1016/j.vaccine.2021.03.018

Guidry, J. P., Laestadius, L. I., Vraga, E. K., Miller, C. A., Perrin, P. B., Burton, C. W. et al. (2021). Willingness to get the COVID-19 vaccine with and without emergency use authorization. American journal of infection control, 49(2), 137-142. https://doi.org/10.1016/j.ajic.2020.11.018

Karlsson, L. C., Soveri, A., Lewandowsky, S., Karlsson, L., Karlsson, H., Nolvi, S. et al. (2021). Fearing the disease or the vaccine: The case of COVID-19. Personality and individual differences, 172, 110590. https://doi.org/10.1016/j.paid.2020.110590

Kissler, S. M., Tedijanto, C., Goldstein, E., Grad, Y. H., \& Lipsitch, M. (2020). Projecting the transmission dynamics of SARS-CoV-2 through the postpandemic period. Science, 368(6493), 860-868. https://doi.org/10.1126/science.abb5793

Kok, G. (2014). A practical guide to effective behavior change: How to apply theory- and evidence-based behavior change methods in an intervention. European Health Psychologist, 16(5), 156-170. https://doi.org/10.31234/osf.io/r78wh

Kok, G., Gottlieb, N. H., Peters, G. J. Y., Mullen, P. D., Parcel, G. S., Ruiter, R. A. et al. (2016). A taxonomy of behaviour change methods: an intervention mapping approach. Health psychology review, 10(3), 297-312. https://doi.org/10.1080/17437199.2015.1077155

Larson, H. J., Jarrett, C., Eckersberger, E., Smith, D. M., \& Paterson, P. (2014). Understanding vaccine hesitancy around vaccines and vaccination from a global perspective: a systematic review of published literature, 2007-2012. Vaccine, 32(19), 2150-2159. https://doi.org/10.1016/j.vaccine.2014.01.081

MacDonald, N. E. (2015). Vaccine hesitancy: Definition, scope and determinants. Vaccine, 33(34), 4161-4164. https://doi.org/10.1016/j.vaccine.2015.04.036

Maddux, J. E., \& Rogers, R. W. (1983). Protection motivation and self-efficacy: A revised theory of fear appeals and attitude change. Journal of experimental social psychology, 19(5), 469-479. https://doi.org/10.1016/0022-1031(83)90023-9

Malik, A. A., McFadden, S. M., Elharake, J., \& Omer, S. B. (2020). Determinants of COVID19 vaccine acceptance in the US. EClinicalMedicine, 26, 100495. https://doi.org/10.1016/j.eclinm.2020.100495

Mo, P. K. H., Luo, S., Wang, S., Zhao, J., Zhang, G., Li, L. et al. (2021). Intention to Receive the COVID-19 Vaccination in China: Application of the Diffusion of Innovations Theory and the Moderating Role of Openness to Experience. Vaccines, 9(2), 129. https://doi.org/10.3390/vaccines9020129

Neumann-Böhme, S., Varghese, N. E., Sabat, I., Barros, P. P., Brouwer, W., van Exel, J. et al. (2020). Once we have it, will we use it? A European survey on willingness to be 
vaccinated against COVID-19. Eur J Health Econ 21, 977-982 (2020). https://doi.org/10.1007/s10198-020-01208-6

Pastorino, R., Villani, L., Mariani, M., Ricciardi, W., Graffigna, G., \& Boccia, S. (2021). Impact of COVID-19 pandemic on flu and COVID-19 vaccination intentions among university students. Vaccines, 9(2), 70. https://doi.org/10.3390/vaccines 9020070

Paul, E., Steptoe, A., \& Fancourt, D. (2021). Attitudes towards vaccines and intention to vaccinate against COVID-19: Implications for public health communications. The Lancet Regional Health-Europe, 1, 100012. https://doi.org/10.1016/j.lanepe.2020.100012

Peters, G.-J. Y. (2014). A practical guide to effective behavior change: how to identify what to change in the first place. European Health Psychologist, 16(4), 142-155. https://doi.org/10.31234/osf.io/hy7mj

Peters, G.-J. Y. \& Crutzen, R. (2018). Establishing determinant importance using CIBER: an introduction and tutorial. The European Health Psychologist, 20(3), pp. 484-494. https://doi.og/10.31234/osf.io/5wjy4

Quinn, S. C., Jamison, A. M., An, J., Hancock, G. R., \& Freimuth, V. S. (2019). Measuring vaccine hesitancy, confidence, trust and flu vaccine uptake: Results of a national survey of White and African American adults. Vaccine, 37(9), 1168-1173. https://doi.org/10.1016/j.vaccine.2019.01.033

Reiter, P. L., Pennell, M. L., \& Katz, M. L. (2020). Acceptability of a COVID-19 vaccine among adults in the United States: How many people would get vaccinated?. Vaccine, 38(42), 6500-6507. https://doi.org/10.1016/j.vaccine.2020.08.043

Rothan, H. A., \& Byrareddy, S. N. (2020). The epidemiology and pathogenesis of coronavirus disease (COVID-19) outbreak. Journal of autoimmunity, 109, 102433. https://doi.org/10.1016/j.jaut.2020.102433

Ruiter, R. A., Kessels, L. T., Peters, G. J. Y., \& Kok, G. (2014). Sixty years of fear appeal research: Current state of the evidence. International journal of psychology, 49(2), 63-70. https://doi.org/10.1002/ijop.12042

Soares, P., Rocha, J. V., Moniz, M., Gama, A., Laires, P. A., Pedro, A. R. et al. (2021). Factors associated with COVID-19 vaccine hesitancy. Vaccines, 9(3), 300. https://doi.org/10.3390/vaccines 9030300

Taylor, S., Landry, C. A., Paluszek, M. M., Groenewoud, R., Rachor, G. S., \& Asmundson, G. J. (2020). A proactive approach for managing COVID-19: The importance of understanding the motivational roots of vaccination hesitancy for SARSCoV2. Frontiers in Psychology, 11, 2890. https://doi.org/10.3389/fpsyg. 2020.575950 
Wang, J., Jing, R., Lai, X., Zhang, H., Lyu, Y., Knoll, M. D. et al. (2020). Acceptance of COVID-19 Vaccination during the COVID-19 Pandemic in China. Vaccines, 8(3), 482. https://doi.org/10.3390/vaccines8030482

World Health Organization. (2014). Report of the SAGE working group on Vaccine Hesitancy. 2014. In Available on:

http://www.who.int/immunization/sage/meetings/2014/october/SAGE_working_group_revised _report_vaccine_hesitancy.pdf (Accessed May 2021)

Xiao, X., \& Wong, R. M. (2020). Vaccine hesitancy and perceived behavioral control: A meta-analysis. Vaccine, 38(33), 5131-5138.

https://doi.org/10.1016/j.vaccine.2020.04.076 